\title{
SYNTHESIS OF NANOSCALE MAGNESIUM OXIDE - Delonix regia AND MANGANESE OXIDE - Delonix regia COMPOSITES AND THEIR COMPARATIVE STUDY OF ADSORPTIVITY ON METHYLENE BLUE
}

\author{
S. Daniel ${ }^{1, *}$ and N. Ramsundram ${ }^{2}$ \\ ${ }^{1}$ Department of Science and Humanities, Kumaraguru College of Technology, \\ Coimbatore-641049, Tamil Nadu, India \\ ${ }^{2}$ Department of Civil Engineering, Kumaraguru College of Technology, \\ Coimbatore 641049, Tamil Nadu, India \\ *E-mail : daniechem61@gmail.com
}

\begin{abstract}
Nanoparticles of Magnesium Oxide and Manganese Oxide were synthesized by a chemical method and coated on Delonix regia-activated carbon separately. The composites were characterized by different methods such as Scanning Electron Microscopy (SEM), Transmission Electron Microscopy (TEM), X-Ray Diffraction (XRD) and Energy Dispersive X-Ray Analysis(EDAX). Batch mode of experiments of Methylene blue dye removal was carried out. The adsorption capacity of Methylene blue dye of nanocomposite of magnesium oxide was observed higher than the nanocomposite of manganese oxide.
\end{abstract}

Keywords: magnesium oxide, chemical method, Delonix regia, composite, activated carbon, methylene blue.

(C) RASĀYAN. All rights reserved

\section{INTRODUCTION}

Enormous growth due to the industrial revolution and subsequent urbanization has generated a large number of aqueous effluents of toxic pollutants in the form of dyes, organic pollutants, heavy metals, $\mathrm{etc}^{1,2}$. Most of the industries had been using coloring chemicals for coloring their products. Effluent discharged from textile mills and dyeing units were enormously colored wastewater due to the presence of a mixture of different dyes. In fact, dyes are aromatic structures of complex in nature and the disposal of the effluent is hardened task. The synthetic dyes are the main cause of several environmental problems, mostly reducing the photosynthetic activity of aquatic plants that reduces penetration of sunlight and being toxic to aquatic organism ${ }^{3}$ Also, the color in water resources poses an aesthetic problem.

Over several years, various wastewater treatment methods had been tried and adsorption has been one of the most accepted techniques in terms of its lower cost, its effectiveness, simplicity and easy operation ${ }^{4,5}$. The usage of nanocomposite materials has been reported for wastewater treatment. The synthesis of nano metal oxide is very important for several reasons that include application in pollution abatement and it is more effective when these nano-sized particles are coated on activated carbon ${ }^{6}$. The nanosize and shape of the metal oxide play a role considered to be very important in the decolorization process and can be controlled by various physical and chemical methods. Metal oxides nanoparticles were synthesized and made use for removal of color from the wastewater effluent. The nanoparticles have the tendency to agglomerate and thus lower the color removal capacity. To prevent the aggregation irreversibly, the nanoparticles were coated on substrates such as activated carbon ${ }^{7}$.

The reason for choosing nano magnesium oxide and manganese oxide is that these have higher affinity for cations compared with $\mathrm{Fe}$ or $\mathrm{Al}$ oxides. Several researchers have suggested applications for nano magnesium oxide and manganese oxide in water and wastewater treatment ${ }^{8-10}$.

Rasayan J. Chem., 12(1), 240-244(2019)

http://dx.doi.org/10.31788/RJC.2019.1214095

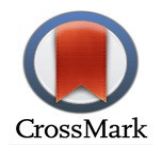


Delonix regia has never been used as a support for nano magnesium oxide ${ }^{11,12}$, but not manganese oxide for the removal of dyes from waste water. To bring the role of the Delonix regia in the MB adsorption, the role of $\mathrm{pH}$ and temperature on $\mathrm{MB}$ adsorption by these composite samples were investigated and the further comparative study also been carried out.

\section{Material and Methods}

\section{EXPERIMENTAL}

\section{Chemical Synthesis of Magnesium Oxide Nanoparticles}

$\mathrm{MgO}$ was synthesized as follows; In $100 \mathrm{ml}$ of water, $6 \mathrm{~g}$ of magnesium chloride and $2 \mathrm{~g}$ surfactant Hexamethylene tetraamine (HMTA) were dissolved and $100 \mathrm{ml}$ of $0.4 \mathrm{~N}$ Sodium hydroxide was added drop by drop with mechanical stirring. At the end of the addition, stirring the solution for $2 \mathrm{~h}$ and the $\mathrm{pH}$ 11 was maintained. The white precipitate obtained was filtered and three times washed with distilled water. The precipitate was dried at $120{ }^{\circ} \mathrm{C}$ for $2 \mathrm{~h}$ and calcined at $800{ }^{\circ} \mathrm{C}$ for $5 \mathrm{~h}^{11}$.

\section{Chemical Synthesis of Manganese Oxide Nanoparticles}

Nanostructured $\mathrm{MnO}_{2}$ was synthesized at ambient condition by reduction of potassium permanganate $\left(\mathrm{KMnO}_{4}\right)$ with Aniline $\left(\mathrm{Ph}-\mathrm{NH}_{2}\right) .3 .16 \mathrm{~g}$ of potassium permanganate and $2 \mathrm{~g}$ of surfactants like Hexamethylene tetraamine (HMTA) were dissolved in $200 \mathrm{ml}$ water. To this $1 \mathrm{ml}$, aniline was added, upon stirring for about $20 \mathrm{~min}$. The precipitate brown in color was obtained and filtered, and the precipitate was washed several times with distilled water followed by acetone. It was then dried in an oven at $50^{\circ} \mathrm{C}$ overnight. The synthesized $\mathrm{MnO}_{2}$ was annealed for $3 \mathrm{~h}$ at $600^{\circ} \mathrm{C}$.

\section{Coating of Nano Particles on Activated Carbon}

The weighed sample of $0.02 \mathrm{~g}$ of nano $\mathrm{MgO}$ was dispersed in $50 \mathrm{~mL}$ methanol with constant stirring. To this dispersed nano $\mathrm{MgO}$ solution, $1.0 \mathrm{~g}$ of Activated Carbon (AC) was added and stirred for $2 \mathrm{~h}$. During this process, the volume of methanol was constantly maintained. The precipitate was filtered and washed 2-3 times with methanol, dried at $60{ }^{\circ} \mathrm{C}$ in a hot air oven and then calcined at $400{ }^{\circ} \mathrm{C}$ under $\mathrm{N}_{2}$ atmosphere. Thus the coating was completed on AC. Similar procedure was followed for nano $\mathrm{MnO}_{2}{ }^{11}$.

\section{RESULTS AND DISCUSSION}

\section{Characterization of $\mathrm{MgO}$ and $\mathrm{MnO}_{2}$ Nanoparticles}

From the XRD pattern of $\mathrm{MgO}$ nanoparticles with peaks and indices values as seen from Fig.-2a which matches with JCPDS card number 75-1525, it could be ascertained that the structure is cubic ${ }^{13}$. The typical patterns (Fig.-2b) show broad diffraction peaks gamma phase $\mathrm{MnO}_{2}$ matches with JCPDS 14-644.

TEM image (Fig.-1) of nano $\mathrm{MgO}$ and nano $\mathrm{MnO}_{2}$ prepared using the chemical method with surfactant at high magnifications and the SAED (selected area electron diffraction) confirms nanocrystalline character of the samples SEM micrograph (Fig.-3) shows the overall appearance of the particles is almost spherical with many irregular-shaped particles with a different size of pores due to the removal of a large number of gases. The gases are formed during the process of synthesis ${ }^{14}$. Porous nature of $\mathrm{MgO}, \mathrm{MnO}_{2}$, and $\mathrm{AC}$ enhances the adsorption characteristics. The EDAX spectra (Figure-4) show the presence of the metals $\mathrm{Mg}, \mathrm{Mn}$ and Carbon in the adsorbents.

Batch mode adsorption experiments with particle size, adsorbent dosage, contact time, $\mathrm{pH}$, initial dye concentration and temperature were studied to fix various factors for effective dye removal. The optimized conditions were $0.1 \mathrm{~g}$ of adsorbent, Methylene blue (MB) dye concentration of $100 \mathrm{mg} / \mathrm{g}, \mathrm{pH}$ 7.0 and $\mathrm{CT}$ of $120 \mathrm{~min}$.

The dye removal by the composites of nano $\mathrm{MgO}$ and nano $\mathrm{MnO}_{2}$ coated Delonix regia activated carbon shows the rapidly increasing adsorption at the initial higher concentration of the dye, then it shows a sudden decrease. The reason for the sudden increase in the adsorption of the adsorbent with the increase of contact time is understood due to the availability of a large number of active sites available on the adsorbent. 
RASĀYAN $J$. Chem.

Vol. 12 | No. 1 |240 - 244| January - March | 2019

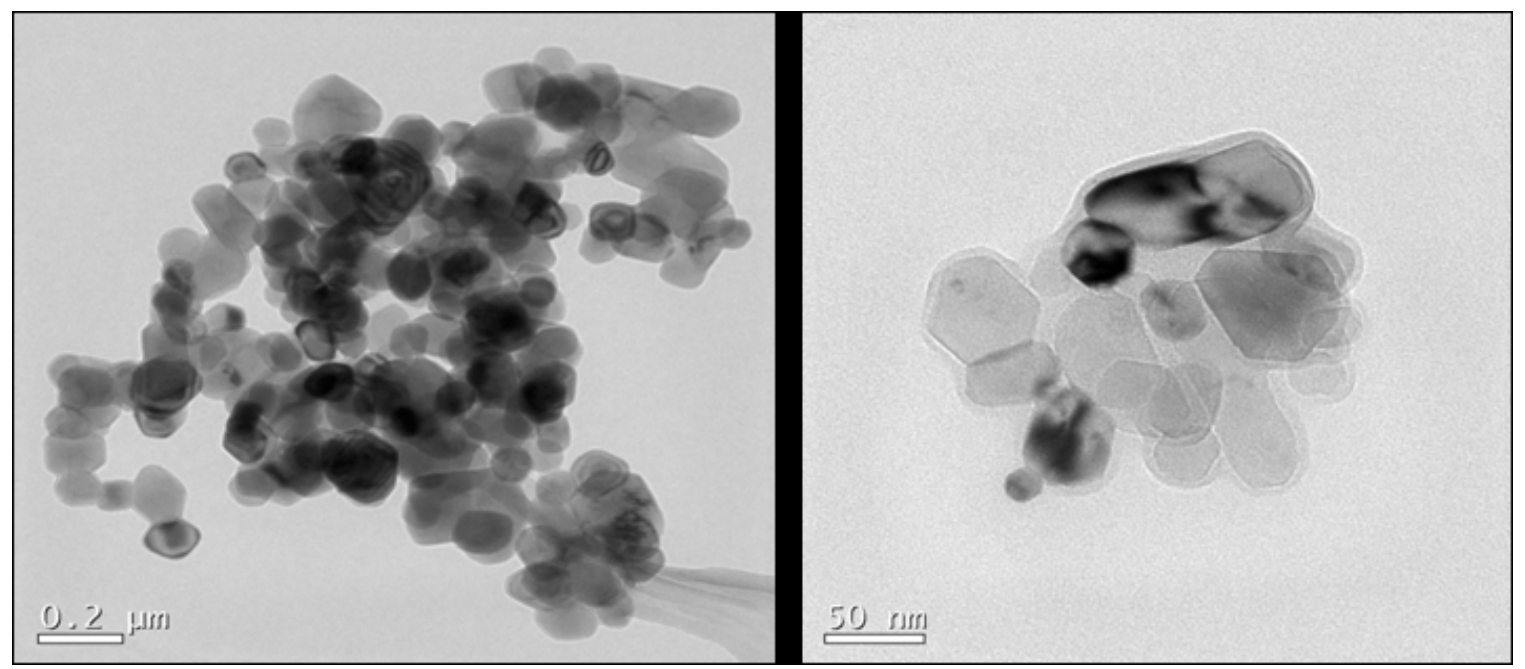

Fig-1: Transmission Electron Microscopy (TEM) Analysis
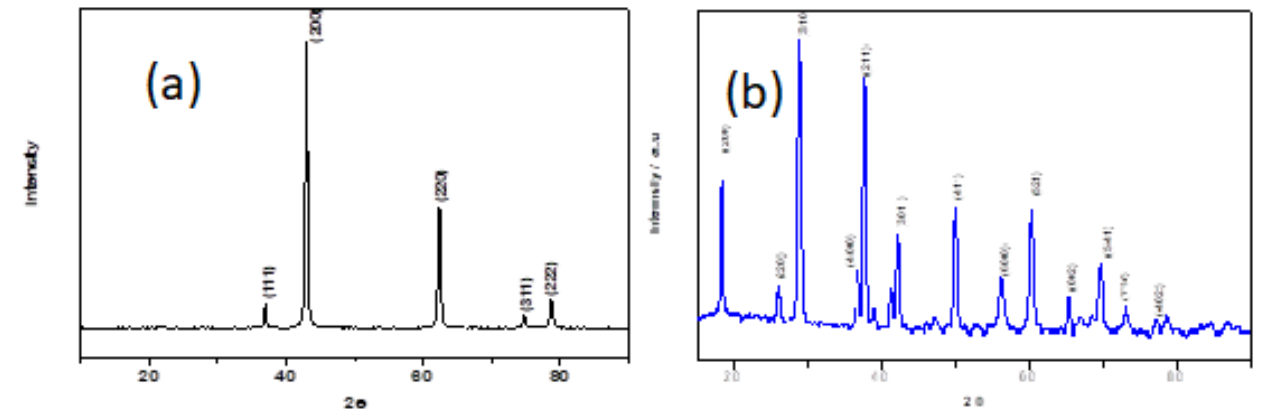

Fig.-2: (a) XRD of Nano $\mathrm{MgO}$ and (b) XRD of Nano $\mathrm{MnO}_{2}$.
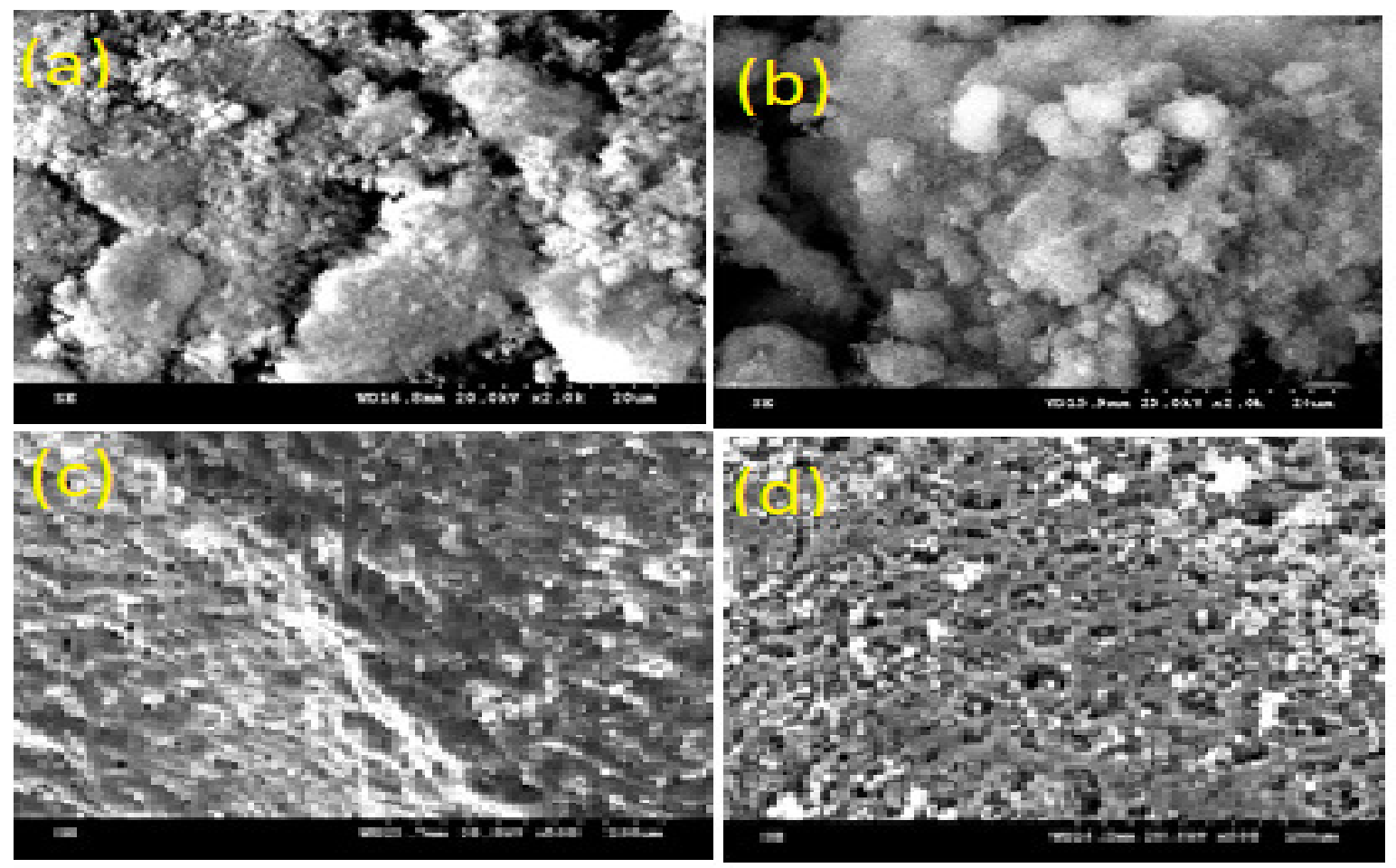

Fig.-3: Scanning Electron Microscopic Images (SEM) of (a) Nano MgO, (b) Nano $\mathrm{MnO}_{2}$. (c) The nanocomposite of $\mathrm{MgO}$ and (d) Nanocomposite of $\mathrm{MnO}_{2}$. 
RASĀYAN J. Chem.

Vol. 12 | No. 1 |240 - 244| January - March | 2019
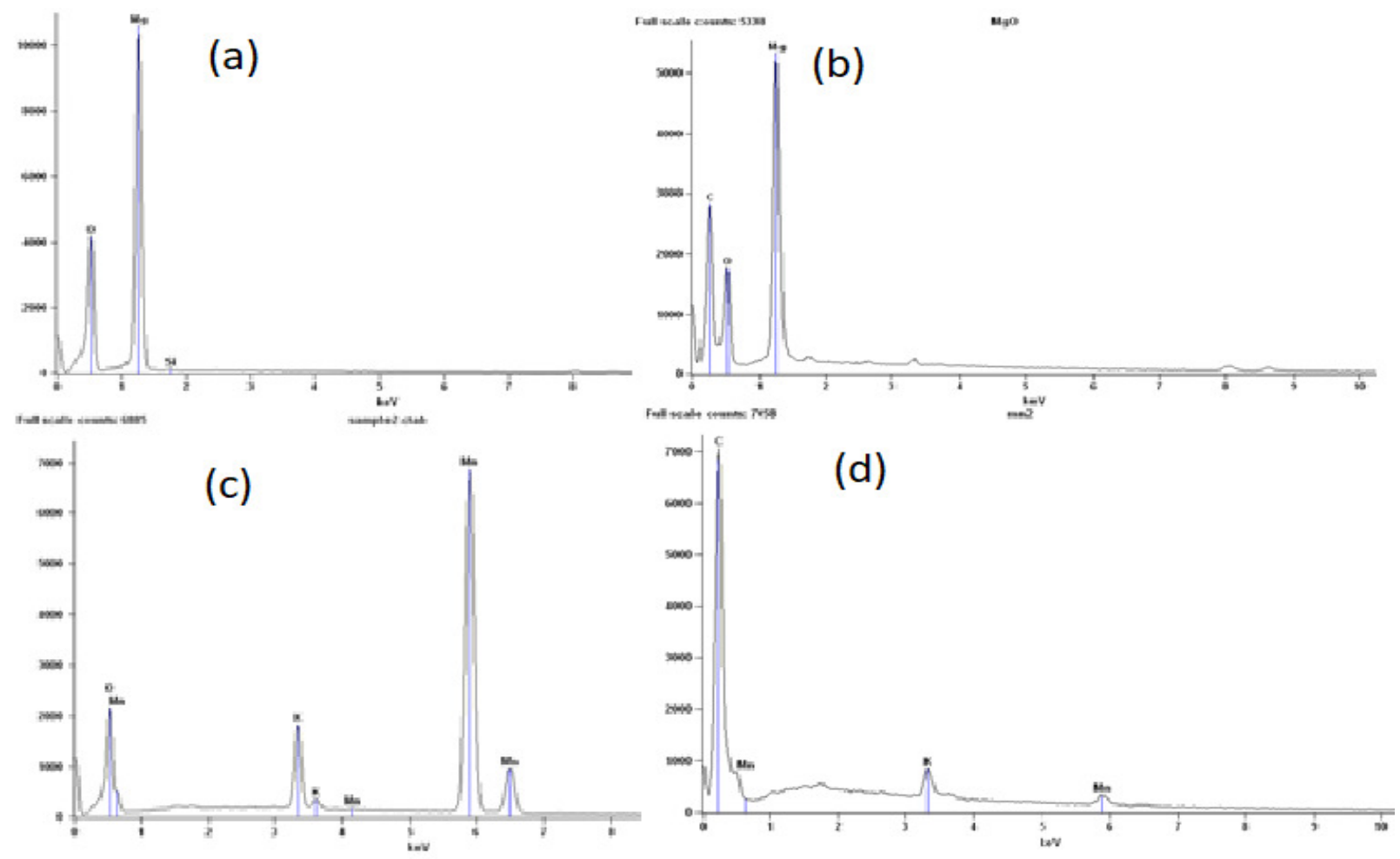

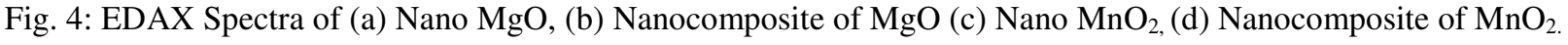

Adsorption decrease after a period of time is due to desorption of dye. The reason could be the increased collisions between dye molecules. The removal percentage of MB was observed for the two different nanocomposites is in the following order:

The nanocomposite of $\mathrm{MgO}>$ Nanocomposite of $\mathrm{MnO}_{2}$.

\section{CONCLUSION}

The results show that highly porous nano $\mathrm{MgO}$ and $\mathrm{MnO}_{2}$ were synthesized by chemical methods with the particle size of 25-40 nm which were coated on Delonix regia activated carbon. The absorptivity of composites of nano $\mathrm{MgO}-$ Delonix regia $\mathrm{AC}$ and nano $\mathrm{MnO}_{2}$ - Delonix regia $\mathrm{AC}$ onto $\mathrm{MB}$ was investigated by batch mode of adsorption studies. The optimum dosage of adsorbent was found to be $0.1 \mathrm{~g}$ as the amount of dye uptake was found to increase with an increase in adsorbent dosage up to $0.1 \mathrm{~g} / \mathrm{L}$ and the $\mathrm{MB}$ dye concentration was optimized at $100 \mathrm{ml} / \mathrm{g}$. It is concluded that the controlled synthesis of nano $\mathrm{MgO}$ and nano $\mathrm{MnO}_{2}$ is viable and $\mathrm{MB}$ dye removal in the case of a composite of nano $\mathrm{MgO}$ - Delonix regia activated carbon is higher than nano $\mathrm{MnO}_{2}$ - Delonix regia activated carbon.

\section{REFERENCES}

1. K. Vijayaraghavan and Y. S. Yun, Biotechnol. Adv., 26(3), 266(2008), DOI: 10.1016/j.biotechadv.2008.02.002

2. F. L. Xu, S.E.Jorgensen, Y. Shimizu and E. Silow, Sci. World J., 2013, 1(2013), DOI: $10.1155 / 2013 / 303815$

3. H. Zollinger, Colour Chemistry-Synthesis, Properties and Application of Organic Dyes and Pigments, NewYork: VCH(1987).

4. P. Nigam, I. M. Banat, D. Singh and R. Marchant, Process Biochem.,31, 435(1996), DOI: 10.1016/0032-9592(95)00085-2

5. V. K. Garg, R. Gupta, B.Yadav and R. Kumar, Bioresour. Technol., 89, 121(2003), DOI: 10.1016/S0960-8524(03)00058-0 
RASĀYAN $J$. Chem.

Vol. 12 | No. 1 |240 - 244| January - March | 2019

6. V. M. Boddu, D. S. Viswanath, and S. W. Maloney, J. Am. Chem. Soc., 91, 1718(2008), DOI: 10.1111/j.1551-2916.2008.02344.x

7. N. A. Sakulchaicharoen, D. M. A. O'Carroll and J. E. B. Herrera, J. Contam. Hydrol.,118 (3-4), 117(2010), DOI: 10.1016/j.jconhyd.2010.09.004

8. M. A. AlGhouti, M. A. M. Khraisheh, M. N. M Ahmad and S. J. Allen, J. Colloid Interface Sci.,287, 6(2005), DOI: 10.1016/j.jcis.2005.02.002

9. M. A. Al-Ghouti, M. A. M. Khraisheh, M. N. Ahmad and S. J. Allen, J. Hazard. Mater., 146, 316(2007), DOI: 10.1016/j.jhazmat.2006.12.024

10. E. Eren, B. Afsin and Y. Onal, J. Hazard. Mater., 161, 677(2009), DOI: 10.1016/j.jhazmat.2008.04.020

11. S. Daniel, P.S. Syed Shabudeen, and A. Basker, J. Environ. Biol., 36(4), 933(2015).

12. S. Daniel, and U. S. Shoba, J. Chem. Pharm. Res., 7(8), 713(2015).

13. Y. Su, H. Wei, Z. Zhou, Z. Yang, L. Wei and Y. Zhang, Mater. Lett., 65, 100(2011), DOI: 10.1016/j.matlet.2010.09.015

14. N. Sutradhar, A. Sinhamahapatra, S. K. Pahari, P. Pal, H. C. Bajaj, I. Mukhopadhyay and A. B. Panda, J. Phys. Chem. C, 115, 12308(2011), DOI: 10.1021/jp2022314

[RJC-4095/2018] 